\title{
PESCA ARTESANAL Y POBREZA EN COMUNIDADES ALEDAÑAS AL GOLFO DE NICOYA
}

\section{ARTISANAL FISHING AND POVERTY IN THE COMMUNITIES NEAR THE NICOYA'S GULF}

\author{
Doris Fernández Carvajal*
}

\section{RESUMEN}

El presente artículo describe la crítica situación que enfrenta la pesca artesanal en el Golfo de Nicoya y cómo ha incidido en condiciones de pobreza en algunas familias de las comunidades de Morales, Costa de Pájaros y Manzanillo de Chomes, provincia de Puntarenas. El mismo, está estructurado en dos partes: en la primera, se presentan algunos datos que muestran la disminución en la captura de los principales recursos pesqueros de la zona, más otros aspectos que permiten dar una visión más integral de la problemática. En la segunda, se muestra el impacto que tiene esta situación en la vida de un grupo de cuarenta mujeres $y$ sus familias.

PALABRAS CLAVE: COSTA RICA * PESCA * CONFLICTOS SOCIALES * POBREZA * RECURSOS PESQUEROS

\section{ABSTRACT}

This article describes the critical situation of traditional fishing at the Nicoya Gulf and how it affects the poverty conditions of some families in the communities of Morales, Costa de Pájaros and Manzanillo de Chomes in the Puntarenas province. The article is structured in two parts: first, it shows some data regarding the decrease in the main fishing resources in the area, as well as other elements that enable a more comprehensive perspective on the issues depicted. The second part shows the impact that this situation has over the life of a group of forty women and their families.

KEYWORDS: COSTA RICA * FISHERY * SOCIAL CONFLICTS * POVERTY * FISHERY RESOURCES 
I. SITUACIÓN DE LA PESCA ARTESANAL EN EL GOLFO DE NICOYA

El Golfo de Nicoya tiene la particularidad de estar conformado por un sistema estuarino, el mismo constituye un cuerpo de agua costero semi cerrado que se conecta con el mar abierto, en el cual el agua salada es diluida por el agua dulce que proviene de los ríos de la zona continental (Blanco, 1994: 23). Esto hace que la zona sea de gran riqueza biológica, permitiendo la presencia $y$ desove de especies marinas de alto valor comercial, como camarones, corvinas, pargos $y$ otras que son de gran aceptación en el mercado nacional e internacional. Algunas estimaciones dicen que este Golfo aporta entre un $50 \%$ y $70 \%$ de los recursos marinos que se consumen en el país.
Este golfo tiene un área de $1340 \mathrm{~km}^{2}$, con una profundidad que va de 0 a los 200 metros, sus costas están cubiertas por 15176 hectáreas de manglares, lo que constituye un importante hábitat para la cría de crustáceos y moluscos, como ostiones, mejillones, almejas, choras y pianguas.

En los alrededores del Golfo, están ubicadas varias comunidades cuyos habitantes por años han hecho de la pesca artesanal su principal medio de subsistencia. Algunas de ellas son: Puerto Thiel, Puerto Pochote, Puerto Moreno, Puerto Níspero, Puerto Jesús, San Pablo, Colorado, Chomes, Cocorocas, Abangares, Paquera, Lepanto, Costa de Pájaros, Morales, Punta Morales, Manzanillo, Chacarita, Cocal y Puntarenas centro. Las comunidades resaltadas con letra negrita son aquellas en donde se ha realizado este estudio (figura 1).

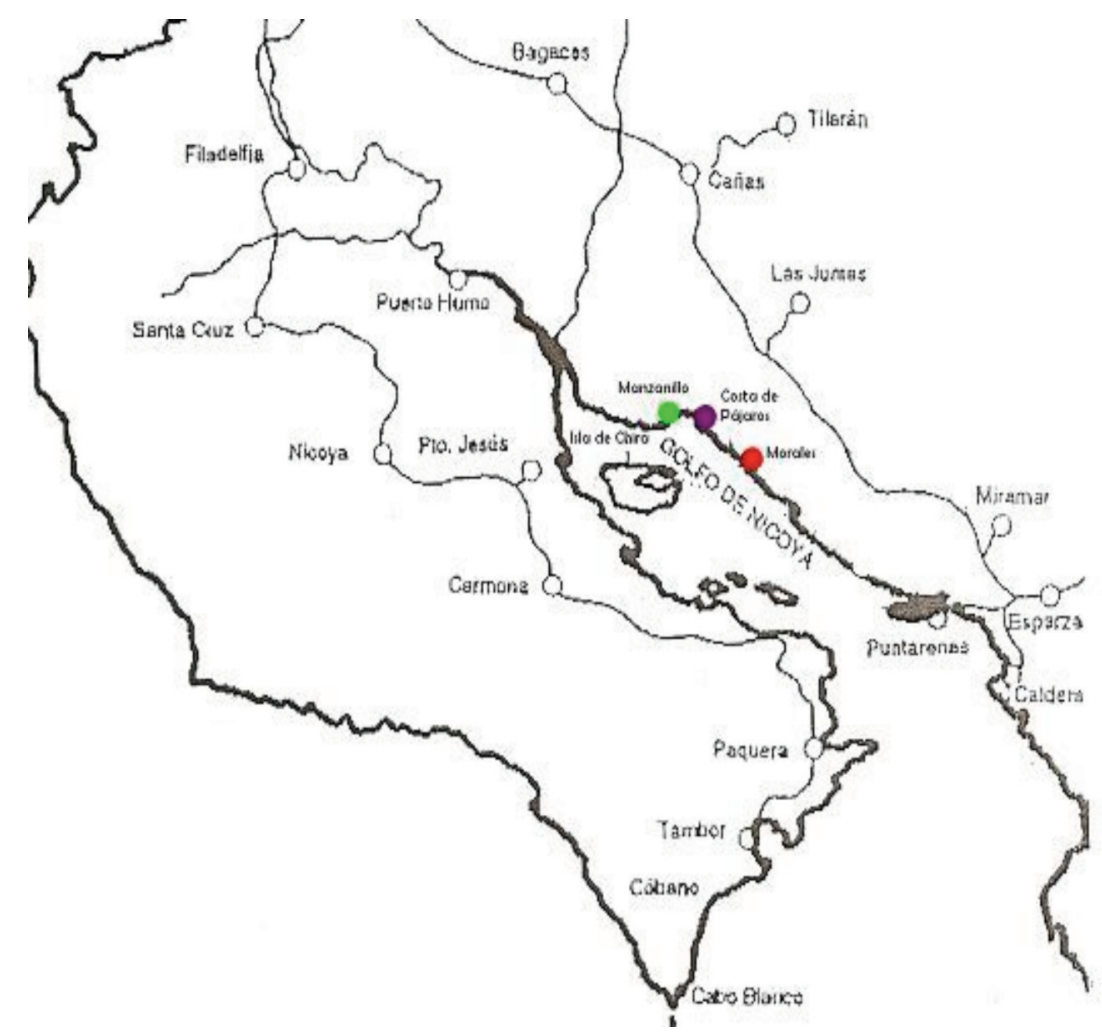


A) TÉCNICAS DE PESCA ARTESANAL

Aunque en Costa Rica se utilizan otras técnicas de pesca, como la semi industrial e industrial, la que se realiza dentro del Golfo de Nicoya se caracteriza por practicarse de manera artesanal, esto significa que el manejo de las artes de pesca se hace de forma totalmente manual. Para este tipo de pesca, generalmente, se utilizan dos tipos de embarcaciones: las pangas, las cuales son movidas por un motor fuera de borda, de baja potencia y por los botes, que son embarcaciones pequeñas movidas por remos.

En la pesca con panga, por lo general, participan entre una y dos personas, dedicándose principalmente a la captura de peces $y$ camarones, en horarios de 10 horas en turnos de día o de noche. Por su parte, los botes se mueven cerca de las playas, entre los manglares y se dedican principalmente, a la recolección de moluscos (almejas, mejillones, pianguas). A este tipo de pesca se le llama también pesca manual $y$ es realizada mayormente por mujeres.

Es importante mencionar que aunque la pesca artesanal tradicionalmente ha sido una actividad realizada por hombres, casi nunca se menciona y se valora la participación de las mujeres $y$ de otros integrantes de la familia, como los niños. Dentro de esta, las mujeres realizan funciones de captura y limpieza del pescado, y muy eventualmente, se le reconoce como una "acompañante" o "ayudante", por lo que su trabajo pasa desapercibido e invisibilizado. De manera similar ocurre con los niños, que desde temprana edad, acompañan a sus padres y otros pescadores en estas tareas y así se van iniciando en el oficio.

En este tipo de pesca se utilizan cuatro artes o formas de pescar que son: el trasmallo, la línea, la cuerda y la manual, el primero es el más utilizado, seguido de la línea y la cuerda en menor proporción.

El trasmallo es una malla o red de nylon llamada popularmente "paño", con un tamaño que oscila entre los 400 y 500 metros de largo por 1,5 metros de ancho. En la actualidad, la luz de malla (tamaño del hueco de la malla) permitida está entre las 3 y las 8 pulgadas, aunque se han venido utilizando de manera ilegal mallas con luz cada vez más pequeñas (2,50 y 2,75 pulgadas). Estos tamaños de red están prohibidos, porque con ellas se capturan especies en su estado juvenil, no permitiendo la reproducción de las mismas. La línea es una cuerda de nylon con una longitud aproximada a los 200 metros que tiene colocados una serie de anzuelos a lo largo de la misma.

\section{CUADRO 1 \\ CAPTURA ANUAL DE LA PESQUERÍA ARTESANAL EN EL GOLFO DE NICOYA EN TONELADAS PERÍODO 1995-2005}

\begin{tabular}{cccccc}
\hline AÑO & TRASMALLO & LÍNEA & CUERDA & MANUAL Y OTROS & TOTAL \\
\hline 1995 & 1444 & 408 & 114 & 8 & 1974 \\
2000 & 2207 & 821 & 81 & 95 & 3204 \\
2005 & 2349 & 754 & 94 & 164 & 3361 \\
\hline PROMEDIO & 2000 & 661 & 96 & 89 & 2846 \\
\hline PORCENTAJE & $70 \%$ & $23 \%$ & $3 \%$ & $3 \%$ & \\
\hline
\end{tabular}

Fuente: Elaboración propia a partir de Estadísticas Pesqueras del Golfo de Nicoya, Costa Rica, 1994-2005. 
Se puede apreciar en el Cuadro $1^{1}$, que un $70 \%$ de la pesca en el Golfo se practica utilizando el trasmallo y un $23 \%$ por medio de la línea. De igual manera, se observa que el uso de trasmallo se ha incrementado en los últimos años, ya que se ha pasado de una captura de 1444 toneladas, en 1995 a 2349, en el 2005. Es importante mencionar que el aumento en la captura que se registra en ese período, no precisamente es indicativo de una mejora en los recursos pesqueros, sino que más bien se debe al uso de mallas de menor luz, o sea de malla prohibida, la cual permite un volumen de captura mayor.

Además de la pesca artesanal, en el Golfo también existe la pesquería de arrastre, la cual es realizada por flota semi industrial, dedicada principalmente a la captura de camarón. Este tipo de embarcación utiliza dos redes colocadas a los lados de la misma. Las potencias de sus motores van entre 170 y 500 HP (Horse Power), siendo el promedio $272 \mathrm{HP}$. Las esloras oscilan entre los 16 y 24 metros, además tienen sistema de enfriamiento propio $y$ emplea un promedio de seis pescadores por viaje.

Según datos de las Estadísticas Pesqueras del Golfo de Nicoya, la pesquería de arrastre de camarón se realizaba en 1952 , con cuatro barcos, mientras que para el 2006, esta flota había aumentado de manera significativa a sesenta barcos arrastreros.

Estos barcos acostumbran ubicarse preferiblemente en la parte externa del Golfo, zona de desove de especies marinas con mayor valor comercial, como la corvina y el camarón. La captura en ese lugar causa un gran daño a dichas especies, ya que no permite su reproducción.

Esta es una de las principales razones que explican la disminución tan significativa que ha registrado la captura de corvina y camarón en los últimos años.

1 Los datos para la elaboración de los cuadros se tomaron de las Estadísticas Pesqueras del Golfo de Nicoya, Costa Rica, 1994-2005. Con la finalidad de ver tendencias más recientes, se solicitó información al Departamento de Estadística del Instituto Costarricense de Pesca y Acuicultura, para obtener datos de los últimos cinco años, no obstante, no fue posible dado que no la tenían procesada.
B) AGENTES SOCIALES PARTICIPANTES DE LA PESCA ARTESANAL

En la pesca artesanal se identifican tres agentes sociales que participan en el proceso: pescador peón, el pescador permisiario y el recibidor de pescado. El primero de ellos es conocido también como "ayudante" o "acompañante", este tipo de pescador no dispone de permiso o licencia para pescar, por lo que trabaja de manera ilegal. Generalmente, no posee el equipo necesario para ello, nos referimos a la panga, el motor y a las artes de pesca. Por estas circunstancias, a este tipo de pescador no le queda alternativa que vender su fuerza de trabajo a otro $\mathrm{u}$ otros pescadores, llamados "permisiarios".

La condición de "ayudante" es muy desventajosa, no solo por los bajos ingresos que devengan, sino porque además no recibe los beneficios del combustible exonerado. Hace unos años, tampoco recibían subsidios en tiempos de veda (período en el cual se prohíbe pescar para que los recursos marinos se puedan recuperar), de manera reciente se le concede esta "ayuda", siempre que el pescador para el que trabaja, lo inscriba como su "ayudante" o "peón".

La relación de trabajo que se establece entre este tipo de pescador y el "permisiario", es que el "ayudante" recibe un 25\% del monto de la venta de lo capturado en una jornada de pesca, una vez que se ha descontado o rebajado el gasto del combustible, el aceite, el hielo y la carnada.

Un ejemplo de la situación que viven estos pescadores, la describe Marco Rodríguez Rivera, pescador de Costa de Pájaros, con 30 años de edad, quien desde muy pequeño incursionó en el mundo de la pesca y tiene 22 años de trabajar de esta manera:

-Yo trabajo con un señor desde hace cinco meses, nosotros trabajamos pescado, salimos como a las cuatro o cinco de la tarde y llegamos al día siguiente en la mañana. Salimos a esa hora echamos las redes, la primera vez la alzamos a las diez y media $u$ once, alzamos $y$ volvemos a tirar $y$ recogemos a las cinco de la mañana y venimos llegando como a las siete $\mathrm{u}$ ocho. Por ejemplo, el viernes 
[28 de marzo 2008], recogimos 19 kilos de primera pequeña y como 7 de clase. Ese día me gané como siete mil colones más o menos, ese día fue un día regular. Cuando está bueno a uno le quedan como diez mil colones o catorce, así. Pero eso no es todo el tiempo es de vez en cuando. A veces uno gana cinco mil, tres mil $y$ a veces no gana nada, si uno tuviera equipo le va mejor, es mejor trabajar por uno mismo (Marco Rodríguez Rivera, pescador de Costa de Pájaros).

El relato anterior es muy ilustrativo, ya que permite dar una idea de la inestabilidad de los ingresos que se perciben de la pesca. Al "ayudante" o "peón" en las comunidades se le percibe como un "taxista pirata", que anda por ahí trabajando al margen de la ley, sin permiso. Esto hace que sea difícil cuantificar la población de pescadores que trabaja de esta forma, ya que estos no aparecen en los registros de información que lleva el Instituto Costarricense de Pesca y Acuicultura (INCOPESCA), quien es el ente rector en esta materia y quien otorga los permisos respectivos.

El señor Álvaro Reina, de la Asociación de Pescadores Artesanales de Puntarenas, consideraba que para el año 2006, existían tres mil pescadores artesanales legalizados (periódico La Nación, 12 de marzo de 2006: 5A) y otros dos mil que trabajaban de manera ilegal.

Por otro lado, se encuentra al "permisiario", quien dispone de una licencia de pesca, ya sea para camarón, pesca o ambos, además, posee su equipo de pesca o sea: una panga, un motor y las respectivas artes. El trabajar de manera legal, le da los beneficios que los primeros no reciben.

El último agente participante en este proceso, es el "recibidor de pescado" o "la pescadería", quien compra el producto directamente a los pescadores. Este por lo general, dispone de un sitio o local para recibir pescado, congeladores para su conservación y es la persona que establece el enlace con los comercializadores del producto.

El "recibidor de pescado" es el primer intermediario dentro de la cadena que se establece hasta que el producto llega al destino final o consumidor. Los precios que pagan a los pescadores son sumamente bajos en relación con los precios que los productos adquieren en el mercado nacional e internacional. Un ejemplo de ello lo encontramos en el precio del camarón jumbo, el cual se paga al pescador aproximadamente a $\$ 5000$ el kilo, mientras que en un supermercado de San José este llega a valer hasta $\$ 12000$ o más.

Al igual que le sucede a otros productores nacionales, los pescadores artesanales no controlan la comercialización de sus productos, generándoles situaciones muy desventajosas, ya que estos son los que realizan la parte más "dura" del trabajo, mientras que los comercializadores son los que perciben las mayores ganancias.

El obtener una licencia para la pesca artesanal, es algo que se ha vuelto prácticamente imposible en los últimos tiempos, esto debido - según expresaron algunos pescadores de Costa de Pájaros con los que se conversporque la asignación de las licencias se hace con criterios políticos que buscan favorecer a personas interesadas en la explotación pesquera a gran escala. Desde el año 2002, no se otorgan nuevas licencias a pescadores artesanales, pero sí se continúan dando a embarcaciones de gran tamaño.

El señor Ronald Rojas Badilla (2008), pescador artesanal de la comunidad de Costa de Pájaros, con 20 años de experiencia en la actividad, se refiere a esta situación de la siguiente manera:

- INCOPESCA es el culpable de que esto no se regule, se ha dado el caso también de personas que compran permisos de pesca, se ha dicho que en Manzanillo y en Chira hay personas con 20 permisos de pesca, lo que pasa es que compran el equipo $y$ utilizan a una $\mathrm{x}$ persona para que salga a nombre de esta persona, pero el equipo de pesca y el permiso nunca va a ser de esta persona. Hablándolo a lo tico, se da el "chorizo", esa es la palabra, la corrupción existe dentro de todos los marcos reglamentarios dentro de la pesca, dentro de ellos INCOPESCA (Ronald Rojas Badilla, pescador de Costa de Pájaros). 
Otra situación anómala descrita por el mismo pescador, se refiere a las presiones a las que están siendo sometidos nuestros mares patrimoniales para su explotación por parte de países con grandes flotas pesqueras.

-Yo tengo a mi suegro que vive aquí cerca, a él le perdieron un permiso de los primeros que daba INCOPESCA, donde él tenía permiso hasta para llevar gente a turistear. ¿Dónde está ese permiso? Ese permiso bien sabemos que fue vendido a un extranjero, a un chino, que eso es lo que más de moda está, así como el caso de mi suegro ha habido casos a nivel del Golfo donde ese permiso se sabe que anda en lanchas mar afuera, en pequeños captura todo, $y$ eso lo digo porque a otro compañero le pasó lo mismo y un día entrando a Puntarenas vio su permiso con todo el número de matrícula en un barco chino. Hoy en día le solucionaron a mi suegro el problema dándole permiso sólo para camarón (Ronald Rojas Badilla, pescador de Costa de Pájaros).

Un ejemplo que sirve para ilustrar lo que nos dijo este pescador, se vivió cuando en el mes de febrero del año 2008, se capturó el barco Tiuna, de bandera extranjera, pescando en aguas territoriales cercanas a la Isla del Coco, con una cantidad importante de toneladas de atún $y$ donde se vio la incapacidad del Estado para sancionar este tipo de faltas.

Otro ejemplo, lo constituye el aleteo de tiburón en nuestras aguas territoriales, también cerca de la Isla del Coco, por parte de flotas japonesas, las cuales han sido denunciadas por la organización Mar Viva (Periódico La Nación, 3 de marzo de 2008: 4A).

\section{C) LA SOBREEXPLOTACIÓN DE LOS RECURSOS} PESQUEROS DEL GOLFO DE NICOYA

En los últimos años a través de diversos medios informativos, se ha venido externando la preocupación de diferentes sectores relacionados con la pesca, como investigadores(as), biólogos(as) y pescadores(as), quienes han venido denunciado la sobreexplotación de los recursos marinos en el Golfo de Nicoya. Un ejemplo de ello se encuentra en la publicación que hace el periódico La Nación con fecha 12 de marzo de 2006, en la cual el señor Marvin Mora, biólogo del Instituto Costarricense de Pesca y Acuicultura (INCOPESCA), expresa que:

Mediante estudios e investigaciones de la Universidad Nacional, el Centro de Investigaciones Marítimas de la Universidad de Costa Rica (CIMAR) y el propio INCOPESCA, se ha logrado determinar que algunos de los principales recursos pesqueros que ahí habitan, tales como las corvinas, los pargos, la sardina y el camarón blanco se encuentran en estado de sobreexplotación (periódico $L a$ Nación: 5A).

Según el señor Mora, lo anterior se origina porque hay un mayor número de embarcaciones pescando y porque se están utilizando artes de pesca prohibidas.

De acuerdo a datos tomados de las Estadísticas Pesqueras del Golfo de Nicoya, se puede observar que el volumen de captura de los principales recursos marinos, no solo del Golfo de Nicoya, sino también de lo que se captura en los dos océanos (Pacífico y Atlántico), ha venido descendiendo, lo que viene a confirmar la preocupación anteriormente planteada (Cuadro 2). 
CUADRO 2

COSTA RICA: DESEMBARQUE DE PRODUCTOS PESQUEROS EN KILOGRAMOS SEGÚN RECURSOS MARINOS PERÍODO 1980-2005

\begin{tabular}{lrrrrrr}
\hline \multicolumn{1}{c}{ RECURSO } & \multicolumn{1}{c}{1980} & \multicolumn{1}{c}{1985} & \multicolumn{1}{c}{1990} & \multicolumn{1}{c}{1995} & \multicolumn{1}{c}{2000} & \multicolumn{1}{c}{2005} \\
\hline Peces & 9280816 & 8268948 & 12271479 & 11530113 & 24206450 & 15787333 \\
Crustáceos & 1747934 & 4564638 & 1991639 & 2286545 & 1489479 & 1302857 \\
Moluscos & 33018 & 58722 & 141489 & 112882 & 119837 & 77484 \\
\hline TOTAL & 11061768 & 12892308 & 14404607 & 13929540 & 25815766 & 17167674 \\
\hline
\end{tabular}

Fuente: Elaboración propia a partir de Estadísticas Pesqueras del Golfo de Nicoya, Costa Rica, 1994-2005.

El cuadro 2 muestra el comportamiento de la captura de los principales recursos marinos de Costa Rica, en los últimos 25 años. Se observa que en la década de 1980 y 1990, se registra un aumento, ya que se pasa de una captura de 11061768 a 14404607 kilogramos. Lo mismo sucede en la década de 1990 al 2000, en la cual se registra un crecimiento significativo en la captura, ya que aumenta en 11411159 kilogramos, es precisamente al año 2005 cuando apreciamos una disminución de 8648092 .
Es importante mencionar que los recursos cuya captura ha disminuido son precisamente los que tienen mayor demanda en el mercado nacional e internacional, como son las corvinas, los pargos y los camarones.

Por otro lado, esta situación también se refleja en una disminución de los desembarques en la pesca artesanal y en los totales en el Golfo de Nicoya. El Cuadro 3 presenta los desembarques en toneladas que han realizado las diferentes pesquerías.

CUADRO 3

DESEMBARQUES ANUALES EN TONELADAS DE LAS DIFERENTES PESQUERÍAS PESCANDO EN EL GOLFO DE NICOYA, EXCEPTO LA PESCA DE ATÚN CON RED DE CERCO PERÍODO 1995- 2005

\begin{tabular}{ccccccc}
\hline AÑO & $\begin{array}{c}\text { PESQUERÍA } \\
\text { ARTESANAL }\end{array}$ & $\begin{array}{c}\text { PESQUERÍA } \\
\text { DE } \\
\text { ARRASTRE }\end{array}$ & SARDINA & $\begin{array}{c}\text { DESEMBARQUES } \\
\text { TOTALES EN EL } \\
\text { GOLFO }\end{array}$ & $\begin{array}{c}\text { DESEMBARQUES } \\
\text { TOTALES EN } \\
\text { COSTA RICA }\end{array}$ & $\begin{array}{c}\text { \% DESEMBARQUES } \\
\text { EN EL GOLFO }\end{array}$ \\
\hline 1995 & 5993 & 2547 & 323 & 8862 & 14031 & 63,2 \\
2000 & 13872 & 1572 & 1610 & 17054 & 25816 & 66,1 \\
2005 & 8177 & 1484 & 2270 & 11931 & 17168 & 60,5 \\
\hline
\end{tabular}

Fuente: Elaboración propia a partir de Estadísticas Pesqueras del Golfo de Nicoya, Costa Rica, 1994-2005.

Como dato importante, se puede observar una disminución en los desembarques que se producen desde la pesca artesanal, ya que esta pasa de 13872 toneladas, en el año 2000 a 8177, en el 2005. También se observa un descenso en la captura en la pesquería de arrastre, pero no en las proporciones que se registran en la artesanal, ya que mientras en la segunda, la disminución en ese mismo quinquenio fue de 88 toneladas (se pasó de 1572 a 1484 toneladas) en la primera, la reducción fue de 5695 toneladas menos (se pasó de 13872 a 8122 toneladas).

Esta situación permite afirmar que el descenso en la captura de recursos marinos 
ha afectado en mayor medida a los pescadores pequeños o artesanales $y$ en menor medida a los pescadores semi industriales, como es la pesquería de arrastre que está concentrada en menos personas.

Con respecto a la captura de camarón, el producto "estrella" del Golfo, particularmente el blanco o jumbo, que tiene el mayor valor comercial, se observa también una disminución en su captura, pero también en las otras especies. El pescador Rojas Badilla, se refiere al descenso en la captura de camarón en los siguientes términos:

-El uso de la malla 2.75 vino a deteriorar la calidad del camarón, porque ya no se captura el camarón grande sino que captura el camarón más pequeño, de menos peso. Con la malla 3 nosotros llegamos a capturar 19 y 22 camarones por kilo, en aquel entonces, para el día de hoy se están capturando con la malla 2.5 hasta 40 camarones para hacer un kilo. Esto también produjo de que el precio disminuyera totalmente, porque los compradores veían que el tamaño más pequeño no era adecuado, no era tan comercial por eso le dan un precio menor (Ronald Rojas Badilla, pescador de Costa de Pájaros).

El relato anterior viene a confirmar como el uso de mallas prohibidas o ilegales ha influido en la captura de un camarón de menor tamaño o joven, afectando la reproducción del mismo. El Cuadro 4 muestra los volúmenes de captura de los diferentes tipos de camarones y en este se puede apreciar muy claramente, el descenso que se ha registrado en la década que va del año 1995 al 2005.

CUADRO 4

CAPTURA ANUAL EN TONELADAS DE ALGUNAS ESPECIES DE CAMARONES CAPTURADAS POR LA PESQUERÍA DE ARRASTRE DENTRO Y FUERA DEL GOLFO DE NICOYA PERÍODO 1995-2005

\begin{tabular}{|c|c|c|c|c|c|c|}
\hline AÑO & BLANCO & $\begin{array}{c}\text { CAFÉ Y } \\
\text { ROSADO }\end{array}$ & FIDEL & TITÍ & CAMELLOS & $\begin{array}{c}\text { CAMARONES } \\
\text { TOTAL }\end{array}$ \\
\hline 1995 & 164 & 266 & 959 & 271 & 339 & 1999 \\
\hline 2000 & 115 & 179 & 333 & 97 & 253 & 978 \\
\hline 2005 & 103 & 160 & 576 & 63 & 125 & 1027 \\
\hline PROMEDIO & 127 & 202 & 623 & 144 & 239 & 1335 \\
\hline PORCENTAJE & $9 \%$ & $15 \%$ & $47 \%$ & $11 \%$ & $18 \%$ & $100 \%$ \\
\hline
\end{tabular}

Fuente: Elaboración propia a partir de Estadísticas Pesqueras del Golfo de Nicoya, Costa Rica, 1994-2005.

Esta disminución se ha dado en todas las especies de camarones, excepto en la especie de camarón Fidel. El camarón blanco es el que registra el menor descenso pero es el que tiene el mayor precio en el mercado, que es de aproximadamente $\$ 5000$ el kilo para el pescador.

Como se señaló anteriormente, la posición del biólogo del INCOPESCA, el señor Marvin
Mora, es avalada por otras opiniones que coinciden en afirmar que la principal causa de la disminución de las capturas de los recursos pesqueros del Golfo de Nicoya, ha sido la utilización de redes de pesca ilegales.

En una conversación sostenida con el señor Ronald Rojas (2008), refiriéndose a las causas que han venido ocasionado la disminución de la pesca, señaló que: 
- Hay que agregar que además que han reducido el tamaño de la malla, han alargado la distancia de los trasmallos, o sea, que hoy en día se encuentran pescadores hasta con 16 y hasta 20 tiras (paños), lógico es que él lo hace, no lo hace sabiendo el daño que causa, sino que entre más meto más agarro, el problema es que a esto se le agrega que hay gente que compra producto pequeño, cuando no debería hacerlo (Ronald Rojas Badilla, pescador de Costa de Pájaros).

Como se puede observar en este comentario, se visualiza la presión que se está ejerciendo sobre los recursos marinos, ya que no solo se utilizan mallas prohibidas, sino que además se ha aumentado el tamaño de las redes o paños para obtener mayores volúmenes de captura.

\section{D) LA DIFÍCIL SITUACIÓN QUE VIVEN LOS PESCADORES(AS)}

Con la finalidad de hacer sostenible la pesca dentro del Golfo, todos los años, el INCOPESCA decreta períodos de veda, en los que se prohíbe practicar la pesca con trasmallo, algunas veces permiten el uso de la línea y la cuerda, $y$ otras veces ninguna.

Como se mencionó anteriormente, por ser el trasmallo el arte más utilizado, durante la veda hay pescadores que suspenden totalmente la pesca, ya sea porque no saben usar otras artes, porque no disponen de estas o bien, porque sencillamente no les gusta utilizarlas, ya que con ellas la captura es mucho menor.

En los últimos años, la veda se ha establecido durante los meses de mayo, junio y julio, por lo cual para compensar los ingresos que dejan de percibir los pescadores(as) durante ese período, se entrega un subsidio a los pescadores "permisiarios" prioritariamente, $y$ en algunas ocasiones, a los "ayudantes", siempre que estos últimos los inscriban.

Ha estado ocurriendo que los "permisiarios", muchas veces reportan como "peón" a la esposa/compañera o a algún familiar cercano (aunque no esté ligado a la pesca), para que este dinero quede "en familia", para así compensar los bajos ingresos durante esos meses. Es así como muchas veces el "peón" no recibe dinero durante el período de veda.

El otorgamiento de este subsidio ha venido generando algunos problemas, no solo por su bajo monto, sino porque además está sujeto a la realización de trabajos comunales como la recolección de desechos en la playa. Esto disgusta muchas veces a los pescadores, porque los hace sentirse denigrados y humillados.

Por ejemplo, en el año 2007, el monto del subsidio que fue entregado a cada pescador fue de $\$ 45000$ mensuales, suma que los pescadores consideraban insuficiente para cubrir las necesidades de una familia promedio de cinco integrantes. Lo más preocupante de esta situación es que el subsidio se entrega a destiempo. Todos los años los pescadores tienen que esperar dos $y$ hasta tres meses para recibir la "ayuda". El principal argumento que dan las autoridades de INCOPESCA para justificar la tardanza del subsidio es que la Institución no dispone de los recursos económicos para ese fin, lo que lo obliga a coordinar con el Instituto Mixto de Ayuda Social (IMAS) la búsqueda de los mismos.

En visitas que se han realizado a las comunidades de este estudio, se ha podido constatar que durante el período de veda, la economía local prácticamente se paraliza. Las personas viven al mínimo, algunas familias con capacidad de ahorro, se preparan para esos meses haciendo una "compra grande" de arroz y frijoles "para irla pasando" y los que no, se ven obligados a comprar fiado o a crédito en las pulperías del lugar con algunos límites, ya que el crédito tampoco puede extenderse por mucho tiempo.

En muchas ocasiones, las personas se ven obligadas a pedir dinero prestado para el pago de los servicios $y$ atender otras urgencias como alguna relacionada con la salud de la familia que no puede postergarse.

Según el periódico La Nación del 22 febrero de 2006, en su página 5, cuyo título decía "IMAS recorta programas para subsidiar la pesca", refleja de muy buena manera, la problemática que se está señalando. Dicho artículo, indicaba que en el año 2005, el Instituto Mixto de Ayuda Social (IMAS), otorgó la suma 
de $\$ 125000$ por concepto de subsidio (por 3 meses de veda) a 1773 pescadores.

Esa partida de $\$ 221.6$ millones fue tomada sacrificando los programas sociales de las personas más necesitadas de la zona, como ayudas a familias pobres, adultos mayores, niños y personas con discapacidad. Según palabras del señor Rodrigo Campos, Gerente General del IMAS, la Institución no dispone de una partida presupuestaria específica para este fin.

El señor Carlos Villalobos Solé, presidente del INCOPESCA, en una entrevista para el Diario Extra del 19 de marzo de 2008, publicada en página 6 , expresó que el principal problema que tiene la Institución es la falta de presupuesto, por lo que se ven imposibilitados para cumplir con todas sus obligaciones y responsabilidades con el sector pesquero nacional. Además agregó, estar en desacuerdo con el subsidio que se le da a los pescadores porque es del criterio que:

... es una cantidad muy baja y al final no se logra nada con esa ayuda al pescador, yo preferiría que hiciéramos un gran esfuerzo por conseguir recursos $y$ emprender un plan de producción masiva que le genere plata al sector pesquero nacional (Diario Extra: 6).

El bajo subsidio otorgado y lo tardío que llega, se convierten en aspectos que hacen insoportable la situación para los pescadores y sus familias durante esos "tres largos meses". Esto constituye el principal motivo que impulsa a los pescadores a no respetar el período de veda establecido, aún estando de acuerdo con su importancia en la recuperación de la biodiversidad marina.

También obliga a los pescadores a desplazarse a lugares más lejanos donde no hay prohibición, incurriendo en algunos riesgos, como fallas en el motor, debido a que el pequeño tamaño de estas embarcaciones y la poca potencia de sus motores no están aptas para distancias largas.

Otro de los mecanismos que ha establecido INCOPESCA para darles apoyo a los pescadores, es el subsidiar el precio del combustible. Este beneficio se otorga exclusivamente a los pescadores con licencia y la cantidad de combustible asignada va en proporción con el tamaño del motor, es decir, a un pescador con un motor de $25 \mathrm{HP}$, recibe un cupón que le da derecho a 400 litros y uno con un motor $40 \mathrm{HP}$, recibe 1050 litros.

Desde noviembre de 2007, se les redujo la cantidad de combustible a los pescadores de las comunidades costeras de la zona del Golfo, con el argumento del mal uso que algunos pescadores venían haciendo del mismo al vender los cupones. Esta reducción de la cuota de combustible vino a agudizar aún más la difícil situación en que viven muchos pescadores y sus familias, ya que la nueva cuota apenas les alcanza para 18 o 19 días, debido a que en cada viaje de pesca se gastan entre 4 o 5 galones, por lo tanto, los demás días tienen que pedir prestado combustible o comprarlo a precio de mercado.

Otra situación importante de mencionar es la forma en que opera el uso del combustible subsidiado para la mayoría de los pescadores. En vista de que el "recibidor de pescado o la pescadería" tiene mejores condiciones como la tenencia de un carro, esto le permite comprar el combustible en grandes cantidades y en estañones. Por ese motivo, es usual que los pescadores le entreguen sus cupones de combustible para que el "recibidor" lo compre y lo transporte.

Esta transacción resulta ser ventajosa para el "recibidor", ya que se gana entre 200 y 300 colones por cada litro de gasolina, por concepto de transporte. El menos favorecido es el pescador, ya que la cantidad de combustible se le disminuye. No obstante, a pesar de la ayuda estatal, la situación de la pesca no muestra mejoría para los pescadores. La publicación que hace el periódico La Nación del 12 de marzo de 2006, página 4A, cuyo titular reza "Pescadores anclados a pobreza pese a millonaria ayuda estatal", señala que:

Pese a las millonarias ayudas estatales en subsidios a los combustibles y la asistencia económica en tiempo de veda, los pescadores artesanales siguen encallados en la pobreza. Esta actividad, según dicen, apenas da para sobrevivir y culpan al gobierno de no apoyarlos. Sin embargo las estadísticas demuestran que el 
Estado lleva años dándoles "oxígeno" y ellos no logran despegar...Pese a las ayudas la actividad pesquera sigue en picada ya que ésta pasó de 26 millones de kilos en el 2002 a 18 millones en el 2005. Prueba de ello es que el Estado ha invertido 19375000 colones otorgados entre los años 2002 y 2005 a unas 2100 familias en las zonas pesqueras del Golfo de Nicoya (La Nación: 4A).

Ante esta situación, la presidenta ejecutiva del INCOPESCA de ese tiempo (2008), la señora Ligia Castro, sostenía que "el Estado no puede eliminar las ayudas al sector pesquero, por que los beneficiarios se han dedicado toda la vida a pescar y solamente esto saben hacer". Una posición diferente tiene el señor Carlos Villalobos, presidente del INCOPESCA de ese entonces, cuando en la entrevista mencionada para el Diario Extra, expresó que:

Se necesitan 2 mil millones de colones para emprender un proyecto que causará un impacto sin precedentes en el país, los vamos a sacar (a los pescadores) por primera vez y para siempre de la pobreza. Vamos a hacer proyectos productivos... Estamos trabajando con el Parque Marino y la Universidad Nacional. Ya comenzamos con proyectos de pescadores asociados, bien organizados. El año pasado liberamos 50000 alevines cerca de la Isla de San Lucas de pargo mancha, desarrollados en el Parque Marino. Queremos 10 o 12 proyectos similares con corvina y camarón (Diario Extra: 6).

Se encontraron dos visiones ante una misma problemática, considerando que esta última es la más viable, pero que requiere además de una fuerte inversión del Estado en la ejecución de acciones, las cuales impliquen la explotación de los recursos marinos de una manera racional como sería la promoción de la maricultura y la debida capacitación de los pescadores para que de manera organizada puedan emprenderla.

De no ser así, se continuará ejerciendo una fuerte presión sobre los recursos marinos, ya que las condiciones de pobreza que afecta a la mayor parte de la población costera los ha hecho altamente dependientes de la explotación de los mismos, convirtiéndose en la única alternativa.

Aunado a lo anterior, hay presión hacia otros recursos naturales de la zona, particularmente, la destrucción de manglares para la instalación de camaroneras y salineras o para la utilización del mangle como leña, ya que ante la carencia de recursos es usual que las familias lo utilicen para cocinar.

La situación antes descrita, genera una especie de ciclo en el que las mismas condiciones de pobreza presionan para hacer un uso cada vez más intensivo de los recursos marinos, que cada día se vuelven más escasos, afectando el equilibrio ecológico $y$ por tanto, vienen a agudizar las ya difíciles condiciones de vida de la población costera.

Según criterio del señor Oscar Luis García (2008), uno de los pescadores con quien se conversó, la situación de la pesca se ha vuelto difícil, "-apenas da para ir sobreviviendo", atrás quedaron los buenos tiempos en que salía abundante pesca, de gran tamaño y que permitía vivir bien $y$ hasta ahorrar. De los tiempos actuales dice:

-Desde hace unos siete años para acá, es donde se ha ido poniendo más feo, yo lo puedo ver en mi cuñado, nativo totalmente de Costa de Pájaros, yo lo llegué a ver a él ahorrar su platita, hoy en día a veces tiene que pulsearla porque a veces no tiene (Oscar Luis García, pescador de Costa de Pájaros).

Para este pescador la situación se ha tornado más difícil, desde unos ocho años para acá, su percepción con base a su experiencia es coincidente con los datos que se han presentado anteriormente, los cuales muestran que el descenso en los volúmenes de pesca se han registrado del año 2000 hasta el presente.

El descenso en la captura de los principales recursos pesqueros tienen un fuerte impacto en las condiciones de vida de cientos de familias que viven exclusivamente de la pesca artesanal, ya que esto se traduce en menores ingresos, como se verá más adelante. 


\section{E) FALTA DE ORGANIZACIÓN DE LOS PESCADORES}

Una de las mayores limitaciones que enfrentan los pescadores artesanales de la zona, es la desorganización en que se encuentran. Ellos perciben que están "organizados" porque pertenecen a una organización local que se llama Coolopez.

Uno de los mayores logros según uno de los pescadores entrevistados, es que se ha logrado establecer un convenio con el Seguro Social para obtener el "seguro del pescador", el cual cubre al trabajador y su familia de la atención básica en salud. Pero en realidad, la función principal que tiene la Coolopez, es la de servir de enlace entre el INCOPESCA y los pescadores de las diversas comunidades, por eso existen comités en Morales, Costa de Pájaros y Manzanillo. Algunas de las funciones que tienen estas organizaciones son: el comunicar a los pescadores las fechas de veda, las del otorgamiento de subsidios en combustible y la organización del trabajo comunal para los pescadores.

En realidad, la Coolopez ha mostrado ser una organización ineficaz para canalizar las principales necesidades que tienen los pescadores artesanales. Esta no ha logrado constituirse es un espacio de presión para la consecución de mejores condiciones de trabajo para los mismos.

Un ejemplo de ello, se encuentra cuando los pescadores reclaman el bajo monto del subsidio y lo retrasado que les llega en períodos de veda. Esta es una situación que han venido enfrentando desde hace varios años; sin embargo, esta molestia no se ha traducido en mecanismos de presión en busca de soluciones.

Otro ejemplo es cuando a los pescadores de Costa de Pájaros se les redujo la cantidad de combustible que se les venía otorgando, esta pasó de 825 litros a 400 litros en noviembre del año 2007. Esa medida vino a afectar a muchos pescadores, debido a que la nueva cuota de combustible no les alcanza para pescar durante todo el mes $y$ las acciones que han emprendido para recuperar ese derecho no están claras tampoco.

También es interesante hacer notar la percepción que tienen algunos pescadores de Costa de Pájaros acerca del INCOPESCA y que posiblemente incida en la poca capacidad organizativa que tienen los pescadores artesanales. El señor Ronald Rojas (2008), se expresa de la siguiente manera sobre esta institución:

- Todo el pescador al que usted le pueda preguntar sobre INCOPESCA le van a decir a usted que INCOPESCA es un monstruo, tan gigante, que un pescador como nosotros, que tenemos un pequeño equipo $y$ que no somos como tal vez como los industriales, de hecho el industrial son millones, no habla de una captura de 10 000 colones, ellos hablan de millones no va a tener recursos monetarios como para pelear contra INCOPESCA (Ronald Rojas Badilla, pescador de Costa de Pájaros).

Se considera que percepciones como la anterior, muestran una actitud derrotista $y$ desesperanzadora con que asumen los pescadores sus problemas en el reclamo de mejores condiciones para sí. Además de los problemas antes mencionados, la pesca artesanal se ve enfrentada a una serie de factores de riesgo que son externos y que junto a los meses de veda, hacen que se reduzcan aún más los días efectivos de pesca.

Algunos de ellos están relacionados con los períodos de vientos, que los pescadores llaman "los nortes" y que suceden durante los meses de diciembre, enero y febrero, los cuales les impiden salir a pescar. Hay que agregar además que los fenómenos del niño y la niña, el primero, produce calentamiento de los mares y propicia la migración de especies hacia aguas más profundas y cálidas, mientras que el segundo, causa aumento en el caudal de lluvias, que lleva gran cantidad de troncos y otros desechos al mar. Esto no solo les impide salir a pescar por el peligro de que un tronco pueda golpear o volcar la panga, sino que además estos rompen y enredan las redes. También hay mareas muy grandes o crecidas que producen mucha corriente y que no son adecuadas para salir a pescar. El señor Oscar Luis García (2008) describe las épocas difíciles para practicar la pesca de la siguiente manera:

- Cuando rompe el norte ni el pescado ni el camarón se puede trabajar, porque 
esas embarcaciones para el mar son como cajitas de fósforo. Cuando entra la corriente del niño, el mar se calienta mucho y los peces buscan más a lo profundo, entonces son épocas malas. También la luminaria, que es como una luz brillante que se hace dentro del mar, es como algo fosforescente, dentro del agua, entonces los peces ven pasar la red $y$ se alejan. Cuando entra el invierno entra mucho el agua mala en grandes cantidades, a veces desea uno ponerse a llorar porque pesa mucho y desea uno dejar los paños tirados, aparte de si te cae en un ojo pica mucho más que el hilo rico. A veces alzar el paño es como alzar el motor de un carro, $y$ hay que irla vaciando, votando $y$ a la vez te pica. Son épocas duras que a veces uno lo hace por necesidad. La niña también trae mucha lluvia, trae mucho palo, se enredan en los paños, el pescador tiene que pagar por todo esto, son riesgos que tenemos los pescadores (Oscar Luis García, pescador de Costa de Pájaros).

Siendo la actividad pesquera la principal fuente de recursos económicos para la gran mayoría de pobladores de la zona en estudio, se puede entender a partir de los datos analizados, que la situación de la misma ha venido deteriorándose. Esto genera un grave impacto para la vida de las mujeres y sus familias, lo cual se traduce en menores ingresos e inestabilidad en los mismos, afectando por tanto, su calidad de vida.

\section{SITUACIÓN ECONÓMICA DE LAS MUJERES Y SUS FAMILIAS}

A continuación, se presenta el impacto que ha tenido la disminución e inestabilidad de los ingresos provenientes de la pesca artesanal, en un grupo de 40 familias, pobladoras de las comunidades citadas. La información sobre ingresos y gastos de las familias fue suministrada en enero de 2008, por las mujeres que participaron en esta investigación.

El cuadro 5 muestra un detalle de las actividades económicas a partir de las cuales se generaban los ingresos de las familias.
CUADRO 5

ACTIVIDADES PRODUCTIVAS DE LAS QUE SE GENERABAN LOS INGRESOS ECONÓMICOS DE LAS FAMILIAS

\begin{tabular}{lcc}
\hline ACTIVIDAD & ABSOLUTO & RELATIVO \\
\hline Pescador con permiso(1) & 16 & 40 \\
Pescador sin permiso (2) & 9 & 22 \\
Operario & 3 & 8 \\
Comerciante de pescado & 1 & 3 \\
Otras actividades & 6 & 15 \\
No aplica & 5 & 12 \\
\hline TOTAL & 40 & $100 \%$ \\
\hline
\end{tabular}

Fuente: Elaboración propia a partir de los cuestionarios.

Como se puede apreciar, un número importante de familias vivían de la actividad pesquera, como ya se había mencionado, esta es la principal generadora de ingresos en estas comunidades costeras. Un $62 \%$ de las familias (25) vivían de la pesca artesanal.

En "otras actividades", se ubicaron aquellas ocupaciones que no estaban relacionadas con la pesca, como fueron: un guarda, un soldador, un electricista $y$ un marinero (estos dos últimos trabajaban fuera de la comunidad). Asimismo, se ubica en esa categoría a un peón agrícola $y$ un chapulinero que se encontraban en la comunidad de Manzanillo, donde hay fincas ganaderas. En estas ocupaciones encontramos a seis hombres.

Los casos que aparecen en el Cuadro 5 como "no aplica", son aquellos casos de mujeres cuyos ingresos se generaban a partir de su trabajo $y / 0$ de pensiones alimentarias de los padres de sus hijos(as).

En un $65 \%$ de las familias (26), solo los esposos o compañeros aportaban al ingreso familiar por lo que un número importante de mujeres se encontraban en una condición de dependencia económica de ese proveedor, ya que esas comunidades no ofrecen opciones laborales más allá de la pesca, ni para hombres ni para mujeres.

Si bien, la mayoría de la mujeres se dedicaban al oficio doméstico, poco más de la mitad (23 mujeres) dijeron realizar otras actividades para mejorar la economía del hogar, como la 
venta de alimentos, ropa, manicure y otros, solo que estas lo hacían de manera esporádica. Ya se sabe que el trabajo de las mujeres dentro del hogar es invisibilizado y no reconocido como tal, aunque es sumamente valioso para la reproducción de la familia y de la sociedad (Benería,1998).

A partir de los ingresos declarados por las mujeres participantes en esta investigación, se determinó que 38 de las 40 familias devengaba ingresos per cápita inferiores a los $\$ 25000$ mensuales, por lo que vivían en condiciones de pobreza, ya que estos se encuentran por debajo de la Línea de Pobreza. Según la Encuesta de Hogares y de Propósitos Múltiples, las cifras básicas sobre pobreza e ingresos para julio de 2007 , era de $\$ 43261$.

De las familias en condición de pobreza, 25 de ellas se encontraban viviendo en pobreza extrema, ya que sus ingresos per cápita eran menores a los $\$ 19000$ mensuales, cantidad que también estaba por debajo de los $\$ 21960$ establecidos para la Canasta Básica de ese mismo año, para la zona rural.

Dentro de las familias en condición de pobreza extrema, se encontró que las cinco que estaban a cargo de una mujer "jefa de familia" presentaban mayores dificultades para mantener a sus hijos(as), ya que no existían en la zona otras alternativas de trabajo más allá de la pesca, al no tener quien cuidara de sus hijos(as) para irse a trabajar fuera $y$ al no recibir pensión alimentaria de los padres de los mismos.

Para un 35\% de las familias (14 familias), sus ingresos se veían incrementados gracias a las becas que recibían de los programas Avancemos y Fondo Nacional de Becas (FONABE), con un monto promedio de $\$ 20000$ por estudiante. Se pudo constatar a partir del relato de algunas mujeres, que este dinero prácticamente se ha incorporado al ingreso familiar para suplir las necesidades básicas, principalmente en alimentación.

Algunos testimonios dan cuenta de la difícil situación en que viven:

- "Se tiene para comer, para ir pasando". - "Sobrevivimos porque comemos aunque sea arroz $y$ frijoles pero nunca se acuestan sin comer".
- "Cuando se está en veda se pasa fatal, cuando la familia es grande la plata no alcanza".

- "En una quincena se compra comida y en la otra se paga luz y agua".

Es importante señalar que alrededor de la medición de la pobreza a partir del ingreso monetario hay una serie de críticas, la principal es que esta resulta ser poco confiable dado que las personas no suelen declarar realmente sus ingresos. No obstante, las debilidades que le puedan atribuir, sigue siendo el principal parámetro en la medición de la pobreza (Sen, 1999 y CEPAL, 2004).

Como se había mencionado, la situación de las familias se vuelve más crítica en tiempos de veda, ya que el subsidio que reciben del Estado resulta ser insuficiente para cubrir las necesidades básicas de la familia. En el año 2007, el monto fue de $\$ 45000$ mensuales por familia. Esto nos dice que un $62 \%$ de las familias (25) que viven de la pesca artesanal, se ven enfrentadas a una situación aún más difícil, ya que el ingreso per cápita mensual se reduce aún más, llegando a ser de $\$ 15000$ para una familia de tres personas, de $\$ 9000$ para una familia de cinco personas y de $\$ 6428$ para una familia de siete personas.

Por otro lado, en relación con los gastos de las familias se determinó que esos se concentraron principalmente en compra de alimentación, el pago de servicios (agua, electricidad y teléfono), gastos de estudio y pago de deudas.

Es importante mencionar que un $92 \%$ (37) de las familias no pagaban casa, ya que llevan años viviendo frente al mar $y$ son viviendas ubicadas dentro de la milla marítima. Las mismas estaban en mal estado $y$ se han construido con materiales de desecho. Como se encuentran dentro de una zona prohibida, no pueden optar por bono o dinero para mejoras, ya que la Ley de Zona Marítimo-Terrestre (ZMT) no lo permite.

El gasto en alimentación absorbía un porcentaje importante del ingreso, para un 55\% de las familias (22), la compra de alimentos consumía entre un 50\% y 75\% del mismo. La dieta básica del lugar es arroz, frijol, pescado y camarón, poca fruta, legumbres y verduras. 
El $80 \%$ de las familias (32) estaban endeudadas por haber comprado a crédito enseres para la casa como: cocina, ventilador (sumamente necesario en estos lugares de clima caliente), televisor, equipo de sonido y sillas. También para la compra de ropa $y$ artículos de cocina. Esta modalidad de compra a "polacos" resultaba ser la única vía posible para estas familias que pagan altos intereses, que muchas veces doblan o triplican el valor del bien.

Volviendo a la situación de las viviendas, se sabe que recientemente la Municipalidad de Puntarenas ha venido realizando visitas a esas comunidades $y$ hay comentarios en el sentido de que esta Institución podría hacer valer dicha Ley y así, desalojar a todas las familias que se encuentran viviendo en esa condición. Ello ha generado algún temor en la población de que a futuro puedan ser desalojados para la explotación de estos como lugares con fines turísticos.

\section{ALGUNAS CONCLUSIONES}

$\diamond \quad$ La pesca artesanal era la principal actividad de la cual se generan los ingresos de las familias, ya que un $62 \%$ de ellas (25) vivían de esta, mientras que un $37 \%$ (15) vivía de otras actividades productivas. La pesca artesanal es una actividad de fuerte tradición en la zona; para muchos hombres es la actividad que han realizado toda su vida y lo único que saben hacer.

$\diamond \quad$ Esta actividad está atravesando una situación crítica debido a un decrecimiento en la captura de los recursos marinos de mayor valor comercial (peces y camarones). Aunado a lo anterior, la zona no ofrece otras alternativas de empleo para hombres ni para mujeres.

$\diamond \quad$ Con todo y el ofrecimiento de las instituciones del Estado por crear opciones laborales (proyectos de maricultura) para contrarrestar los efectos negativos del descenso en la pesca artesanal, los mismos aún no despegan con consecuencias sumamente peligrosas en el mediano plazo. Algunas mujeres mencionaron que sus esposos o compañeros han pensado en desplazarse a otros lugares (migrar) en busca de otros trabajos fuera del lugar, con las consecuencias de desintegración que esto podría ocasionar a las familias.

$\diamond \quad$ Tomando como referencia los ingresos de las familias, se puede concluir que 38 de las 40 familias que participaron en este estudio, vivía en condiciones de pobreza con ingresos per cápita inferiores al monto establecido para la Línea de Pobreza a julio del año 2007. De estas familias, 25 vivían en pobreza extrema, ya que sus ingresos estaban por debajo del monto de la Canasta Básica de ese mismo año.

$\diamond \quad$ Un 65\% de las familias vivía del ingreso que aportaba el esposo o compañero, aunque un $55 \%$ de las mujeres realizaba otro tipo de actividades de manera esporádica, para mejorar la economía familiar. Esta situación colocaba a las mujeres en una condición de vulnerabilidad al ser dependientes económicamente de sus parejas.

$\diamond \quad$ Las becas de estudio que recibían algunas familias vinieron a constituir un complemento muy importante en el ingreso de las mismas. Este dinero se utilizaba para cubrir una de las necesidades más importantes de la familia como es la alimentación. Se hace necesario mantener y aumentar el apoyo a través de becas a estudiantes, a fin de detener la deserción escolar y evitar de esta manera que el ciclo de la pobreza se sigua reproduciendo en nuevas generaciones.

$\diamond \quad$ Los ingresos más bajos se registraron en aquellas familias que estaban a cargo de una mujer sin recibir pensiones alimentarias, con el agravante de no tener con quien dejar a sus hijos(as) para salir a trabajar. Los Programas de Cuido de la administración de Laura Chinchilla van dirigidos a este tipo de mujeres, como un medio de combatir la pobreza.

\section{BIBLIOGRAFÍA}

Blanco Brenes, Oscar. La cuenca del Golfo de Nicoya: un reto al desarrollo sostenible. San José, Costa Rica: Editorial Universidad de Costa Rica, 1994. 
Benería, Lourdes. "La mujer y el género en la economía: un panorama general". Economía y Género. Macroeconomía, Politica Fiscal y Liberalización, Análisis de su impacto sobre las mujeres. Paloma de Villota (ed.). Barcelona: UNIFEM Icaria Editorial, 1998.

CEPAL-UNIFEM. "Entender la pobreza desde la perspectiva de género". Serie Mujer y Desarrollo 52. Santiago de Chile: CEPALUNIFEM-República de Italia, 2004.

Instituto Nacional de Estadística y Censos (INEC). Cifras Básicas sobre Pobreza e Ingresos para Julio 2007. Costa Rica: INEC, 2007.

Sen, Amartya. Desarrollo y Libertad. Barcelona: Editorial Planeta, 1999.

UNA-JICA-InCOPESCA. Estadísticas Pesqueras del Golfo de Nicoya, Costa Rica. 1994-2005. Heredia, Costa Rica: UNA-JICA-INCOPESCA, $2007 \mathrm{a}$.

UNA-JICA-INCOPESCA. Presentación de conclusiones y recomendaciones del Proyecto Manejo Sostenible de la Pesquería para el Golfo de Nicoya. Puntarenas. 2002-2007. Heredia, Costa Rica: UNA-JICA-INCOPESCA, 2007b.
PERIÓDICOS

Diario Extra. "La tentación del narcotráfico es muy grande para los pescadores". Costa Rica. 19 de marzo de 2008: 6.

Periódico La Nación. "Pescadores anclados a la pobreza pese a millonaria ayuda estatal". Costa Rica. 12 de marzo de 2006: 4A.

Periódico La Nación. "Imas recorta programas para subsidiar la pesca”. Costa Rica. 22 de febrero de 2006: 5A.

Periódico La Nación. "Error legislativo deja sin protección la Isla del Coco". Costa Rica. 3 de marzo de 2008: 4A.

\section{ENTREVISTAS}

Ronald Rojas Badilla, pescador artesanal, Costa de Pájaros, 8 de julio de 2008.

Oscar Luis García García, pescador artesanal, Costa de Pájaros, 8 de julio de 2008.

Marco Rodríguez Rivera, pescador artesanal, Costa de Pájaros, 9 de julio de 2008.

Fecha de ingreso: 26/03/2012

Fecha de aprobación: 24/08/2012 